\title{
Skin grafting in the treatment of hard-to-heal leg ulcers
}

\author{
Giovanni Mosti, Vincenzo Mattaliano, Pietro Picerni, Nicola Angelotti, Costantino Christou
}

Angiology Department, Clinica MD Barbantini, Lucca, Italy

\begin{abstract}
Some risk factors or comorbidities may make Chronic Leg Ulcers (CLU) very difficult to heal. These ulcers are usually defined refractory ulcers and may require an in-hospital intensive care to increase the healing rate. Aim of this retrospective study was to assess if our clinical routine in hospitalized patients, made up with surgical debridement followed by donor skin grafting (allografts), may favor the ulcer healing. The records of 120 patients (55 males and 65 females; mean age $73.9 \pm 11.3$ years) with ulcers greater than 100 $\mathrm{cm}^{2}$ and lasting for more than 1 year were analyzed. The median ulcer size was $165 \mathrm{~cm}^{2}$ (IQR 130-250 $\left.\mathrm{cm}^{2} ; \mathrm{range} 100-1000 \mathrm{~cm}^{2}\right)$. The median ulcer duration was 24 months (IQR 16-32 months; range 12-300 months). The ulcer pathophysiology was venous in 74 patients, arterial in 21, mixed in 12, vasculitis in 5 and post-traumatic in 8 patients. After debridement the patients were submitted to allograft procedures (single or multiple) up to the ulcer healing. When allograft was able to create an effective granulation tissue and reduce the ulcer size an autograft was performed to get the ulcer closure. 109 patients healed and 11 were lost at follow-up. 65 patients healed just with one allograft in 16 weeks (IQR 13-21 weeks). 42 patients healed with 2 procedures in 20 weeks (IQR 18-23 weeks). 31 of them received a final autograft while 11 healed with two allografts. 2 patients with an ulcer surface of $200 \mathrm{~cm}^{2}$, both affected by CLI, healed with 3 allografts procedures in 40 and 33 weeks, respectively. Pain and exudate amount were significantly decreased and even disappeared after the first allograft. Allografts alone or followed by an autograft are able to get the ulcer healing also in case of extensive and long lasting ulcers refractory to all previous treatments.
\end{abstract}

\section{INTRODUCTION}

Chronic leg ulcer (CLU) is a discontinuity of the epidermis and dermis in the lower limb of more than 6 weeks duration. ${ }^{1}$ CLUs do not show any tendency to a spontaneous healing as underlined in many documents and guidelines. ${ }^{2-8}$ When CLU may be associated with risk factors

Correspondence: Giovanni Mosti, Angiology Department, Clinica MD Barbantini, Via del Calcio 2, Lucca, Italy.

Tel.: 0583.91971.

E-mail: giovanni.mosti10@gmail.com

Key words: Chronic leg ulcer, venous ulcers, arterial ulcers, mixed ulcers, skin grafting, allograft, autograft.

Contributions: the authors contributed equally.

Conflict of interest: the authors declare no potential conflict of interest.

Funding: none.

Received for publication: 2 November 2017.

Revision received: 20 November 2017.

Accepted for publication: 20 November 2017.

This work is licensed under a Creative Commons Attribution NonCommercial 4.0 License (CC BY-NC 4.0).

(C) Copyright G. Mosti et al., 2018

Licensee PAGEPress, Italy

Italian Journal of Wound Care 2018; 2(1):1-7

doi:10.4081/ijwc.2018.18 making the spontaneous healing particularly hard to get: large size and/or long-duration, skin loss involving epidermis, dermis and sometimes subcutaneous tissue, ankle, knee or hip arthritis, fibrin slough covering more than 50\% of ulcer surface, calf muscle pump impairment, obesity, arterial disease. ${ }^{9,10}$ These are defined hard-to-heal CLU. In these cases even an adequate care including an extensive diagnostic protocol, the treatment of the underlying disease and a correct local care (proper dressing, compression therapy and physical activity) often fails to achieve the ulcer healing. In addition it may be extremely expensive due to endless treatment, increasing costs for frequent dressing and bandage changes, antibiotics when infection occurs, pain-killers, admission to hospital in case of complications. In these circumstances, surgical debridement and skin grafting are often offered as an ultimate option when the standard treatment protocol fails. An autograft is usually performed in case of very superficial skin ulcers while skin substitutes or skin from donors are used to rebuild the deep layers and to allow either a spontaneous healing or a final autograft to complete healing. Aim of this study is to report the more recent retrospective data on the outcomes we recorded by using surgical debridement and skin grafting in our patients suffering from hard-to-heal CLU.

\section{PATIENTS AND METHODS}

This is a retrospective analysis in accordance with the Ethical Principles for Medical Research Involving Human Subjects (Helsinki-declaration). 


\section{Case series}

Within a total number of 740 patients admitted to our hospital for hard-to-heal CLU in the last three years we retrospectively reviewed the records of patients affected by ulcers characterized by surface greater than $100 \mathrm{~cm}^{2}$, skin loss involving epidermis, dermis and subcutaneous tissue, duration longer than 1 year and showing no sign of healing tendency.

Inclusion criteria: patients of both sex, every age, affected by leg ulcers with surface $>100 \mathrm{~cm}^{2}$ and duration $>1$ year not showing healing tendency, with different pathophysiology and comorbidity.

Exclusion criteria: leg ulcers with size $<100 \mathrm{~cm}^{2}$, duration $<1$ year, not involving dermal and subcutaneous layers, showing signs of healing tendency. Ulcers caused by not surgically treatable critical limb ischemia (CLI), due to local or general contraindication to revascularization, were included, although CLI is one of the usual exclusion criteria in randomized clinical trials.

\section{Protocol}

The diagnostic protocol of all the patients admitted to our hospital includes family and clinical history, blood tests, ulcer examination with ulcer size measurement and ulcer bed inspection, swab to assess the bacterial load in case of clinically infected wound, Doppler examination with Ankle Brachial Pressure Index (ABPI) measurement and Duplex examination. When Doppler and Duplex examination do not reveal any sign of vascular disease, or in every ulcer with atypical aspect, dermatologic and rheumatologic consultations, blood tests for rheumatologic disease and ulcer biopsy are performed.

The therapeutic protocol of these patients includes the maintenance of their baseline pharmacologic treatment; antiplatelet drugs are added in patients with arterial involvement when not yet included in the routine treatment. Intravenous prostaglandin Iloprost is administered to patients with not surgically treatable CLI during the hospitalization period. Antibiotics are added in patients with clinical signs of critically colonized or clinically infected wounds according to microbial sensitivity test. All the patients are submitted to compression therapy by inelastic bandages exerting a strong pressure in case of venous ulcers, and a reduced pressure in all other cases. A bandage exerting a very light compression pressure, just to retain the dressing, was applied to patients with critical limb ischemia. In addition the patients are recommended to walk or stay in bed to remove leg edema when requested.

Venous ablation is not performed before or simultaneously with the skin graft because we want to evaluate the effectiveness of the single grafting procedure on wound healing. Venous procedures are postponed after the wound healing.
In the surgical theatre the ulcers are submitted to surgical or Hydrosurgical debridement to completely remove necrotic tissue, fibrin slough, bacterial overload and to prepare the ulcer bed and the edges. ${ }^{11,12}$ After preparation, a donor skin graft (hereafter allograft) is performed covering the whole ulcer bed and slightly exceeding the ulcer edge. No stiches are used. The graft is covered by antiseptic non-adherent gauze. Finally the inelastic bandage is re-applied with the same application system as in the pre-op period.

Patients are requested to remain in bed for two days; a slight active mobilization is allowed in the third day. They are usually discharged on fourth/fifth day after the grafting procedure.

During the follow-up the patients are visited on a weekly base until allograft remains on the ulcer bed. Dressing and bandage are reapplied at every visit.

Further procedures are scheduled based on observed outcomes. When the first allograft produces the rebuilding of deep layers and a flesh granulating tissue growth with an ulcer size roughly unchanged or slightly reduced, a new allograft is performed. When ulcer bed improvement is associated with an ulcer surface significantly smaller compared to baseline a new graft is performed. An autograft is applied only if ulcers become smaller than $200 \mathrm{~cm}^{2}$, if contraindications do not exist and patients do not refuse their own skin harvesting procedure (Figures 1 and 2). In any other case a new allograft is applied. When the ulcer becomes smaller and in the epithelization phase we keep on with moist dressings and compression therapy until we get the ulcer healing. No further procedure is performed in case of ulcer healing. In this case the patient is advised to keep on compression by elastic stocking. In case of ulcer caused by superficial vein incompetence the patients are submitted to vein ablation to prevent recurrences. ${ }^{13}$

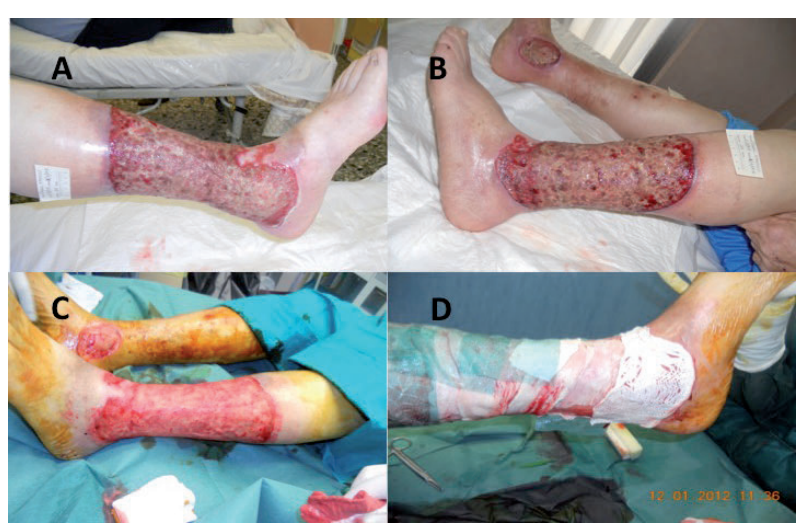

Figure 1. Medial (A) and lateral (B) aspect of the ulcer eg. Same ulcer after treatment by Versajet (C) and after allograft (D). 
Primary outcome was considered the healing time (in weeks). Secondary outcomes were considered pain level evaluated by Visual Analogue Scale (VAS: 0 no pain; 10 very strong pain) and exudate amount reduction.

For exudate evaluation we used the Falanga score ${ }^{14}$ and, accordingly, scored the exudate amount as i) minimal, ii) partially moderate or iii) uncontrolled.

\section{Skin from donors}

The donor skin can be provided by the Tissue Banks which are in charge for skin procurement, processing and storage according to the European and National guidelines. ${ }^{15,16}$ The skin grafts are procured only after a strict selection of the donors who must be submitted to autopsy or cadaveric inspection. Evaluation of any candidate for the donation of tissues and cells includes comprehensive collection of medical and social (personal, behavioral) information (including travel history), physical examination, serological and microbiological testing. The selection criteria for deceased and living donors of tissues and cells are specified by European and National directives. ${ }^{17,18}$ Briefly, unknown death cause, infectious disease (hepatitis, AIDS, syphilis), cancer, dysplastic nevus syndrome, collagen diseases, active dermatitis, chemotherapy, radiotherapy, immunosuppressive drugs intake are exclusion criteria.

Serological screening includes testing for HIV, hepatitis $\mathrm{B}$ and $\mathrm{C}$ virus, syphilis, human T-lymphotrophic virus, CMV. Microbiological tests are performed to rule out tissues contamination for bacteria and fungi. Only microbially negative skin can be released for grafting. Donor skin can be processed to obtain skin grafts or dermal grafts only (de-epidermized dermis; DED) and finally stored by means of three storage systems: cryopreservation at $-80^{\circ}$, storage in a high concentrated glycerol solution or lyophilisation.

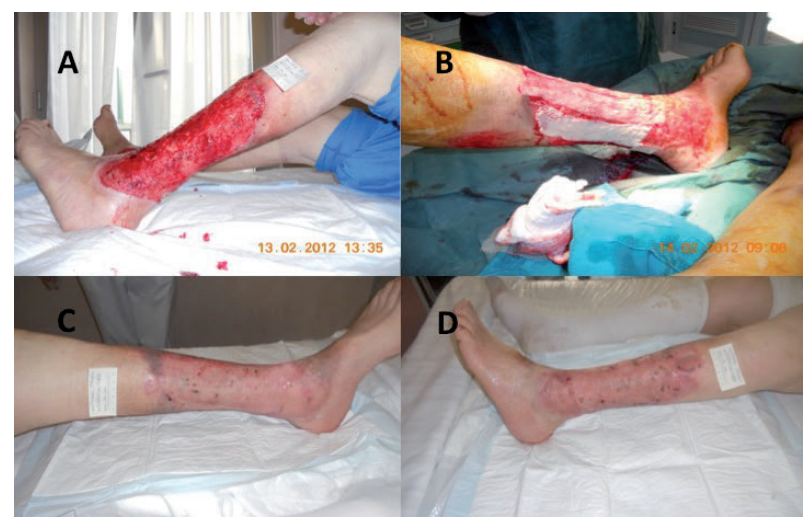

Figure 2. One month later same ulcer after allograft detachment (A), after autograft (B) and after ulcer healing on medial (C) and lateral (D) aspect of the lower leg.
Glycerolized and cryopreserved skin is different mainly regarding tissue viability. Cryopreserved tissue is viable and can be integrated onto the wound bed. Glycerolized skin is not viable even maintaining all the structural and mechanical properties and represents an ideal biologic dressing. In our patients we used cryopreserved DED.

\section{Statistical analysis}

Medians with interquartile ranges and maximal and minimal values are given. Kruskall-Wallis test was used to compare the healing rate in different groups of patients depending on pathophysiology, ulcer size and duration, number of grafting procedures. The nonparametric Spearman rank test was used to quantify correlations. Differences with a $\mathrm{P}<0.05$ were considered statistically significant. The graphs and the statistical evaluations were generated by using Graph Pad Prism, version 6 software (Graph Pad, San Diego, CA).

\section{RESULTS}

The records of 120 patients (55 males and 65 females; mean age was $73.9 \pm 11.3$ years; age range between $42-93$ years) with 139 ulcers were analyzed.

The ulcer number was just one in 103 in patients, more the one in 17 patients. In case multiple ulcers at least one had to be greater than $100 \mathrm{~cm}^{2}$. The median ulcer size was $165 \mathrm{~cm}^{2}$ (IQR 130-250 $\mathrm{cm}^{2}$; range 100-1000 $\mathrm{cm}^{2}$ ). The median ulcer duration was 24 months (IQR 16-32 months; range 12-300 months).

The ulcer pathophysiology was: superficial vein incompetence (SVI) in 30 patients, deep venous incompetence (DVI) in 30 patients, both SVI and DVI in 14 patients, moderate arterial disease (AD) with ABPI $>50$ and $<80$ in 13 patients; critical limb ischemia (CLI) without any revascularization possibility in 8 patients. Twelve patients were affected by mixed arterial and venous disease (MD), five by vasculitis (Vas) and eight by post-traumatic ulcers (PT) without any vascular involvement. Patients comorbidities: smoking habit in 17 patients, diabetes mellitus in 24 patients, arterial hypertension in 74 patients, hypercholesterolemia in 24 patients, sedentariness in 42 patients. 20 patients had no comorbidities, 43 just 1 and 57 associated comorbidities (Table 1).

Following ulcer bed preparation and bacterial load control all patients were submitted to an allograft due to skin loss involving dermal and subcutaneous layers. During the follow-up, five patients died. One patient was amputated due to worsening of the leg ulcers and untreatable pain and 5 patients were lost at follow up.

All the remaining 109 patients healed. 65 patients with an ulcer surface of $144 \mathrm{~cm}^{2}$ (IQR $120-200 \mathrm{~cm}^{2}$ ) healed just with one allograft in 16 weeks (IQR 13-21 weeks). 
42 patients with an ulcer surface of $210 \mathrm{~cm}^{2}$ (IQR 160$300 \mathrm{~cm}^{2}$ ) healed with 2 procedures in 20 weeks (IQR 1823 weeks). 31 of them received a final autograft while 11 healed with two allografts. 2 patients with an ulcer surface of 210 and $190 \mathrm{~cm}^{2}$, both affected by CLI, healed with 3 allograft procedures in 40 and 33 weeks, respectively.

The healing time is related to the ulcer size and duration: the larger the ulcers size, the longer the ulcer duration the longer the healing time (Figure 3).

Pain was significantly reduced by grafting procedures even after the first allograft from 7 (IQR 4-8; range 1-10) to 0 (IQR 0-2; range $0-6)(\mathrm{P}<0.0001)$. Some difference in pain was reported according to pathophysiology. Venous and post-traumatic ulcers were the less painful and grafting resulted in the best outcomes (pre-op VAS 5; IQR 47; post-op VAS 0; IQR 0-1) compared to arterial and vasculitic ulcers with the ulcers in CLI being the most painful and less responsive to treatment although with minimal residual pain (pre-op VAS 8, IQR 7-9; post-op VAS 2, IQR 1-3).

Table 1. Demographic characteristics.

\begin{tabular}{|c|c|}
\hline Patients (number and sex) & $120(55 \mathrm{~m} ; 65 \mathrm{~F})$ \\
\hline Age (years) & $73.9 \pm 11.3 ;$ range $42-93$ \\
\hline Ulcer number & 139 \\
\hline Ulcer size $\left(\mathrm{cm}^{2}\right)$ & $165 \mathrm{~cm}^{2}$ (IQR 130-250; range $\left.100-1000\right)$ \\
\hline Ulcer duration (months) & 24 (IQR 16-32; range 12-300) \\
\hline Deep venous incompetence (DVI) & 30 patients \\
\hline $\mathrm{SVI}+\mathrm{DVI}$ & 14 patients \\
\hline Arterial disease & 13 patients \\
\hline Critical limb ischemia (CLI) & 8 patients \\
\hline Mixed ulcers (arterial + venous disease) & 12 patients \\
\hline Trauma & 8 patients \\
\hline Comorbidities yes/no & $80 / 20$ patients \\
\hline Lost at follow-up/complete treatment & 11/109 patients \\
\hline
\end{tabular}
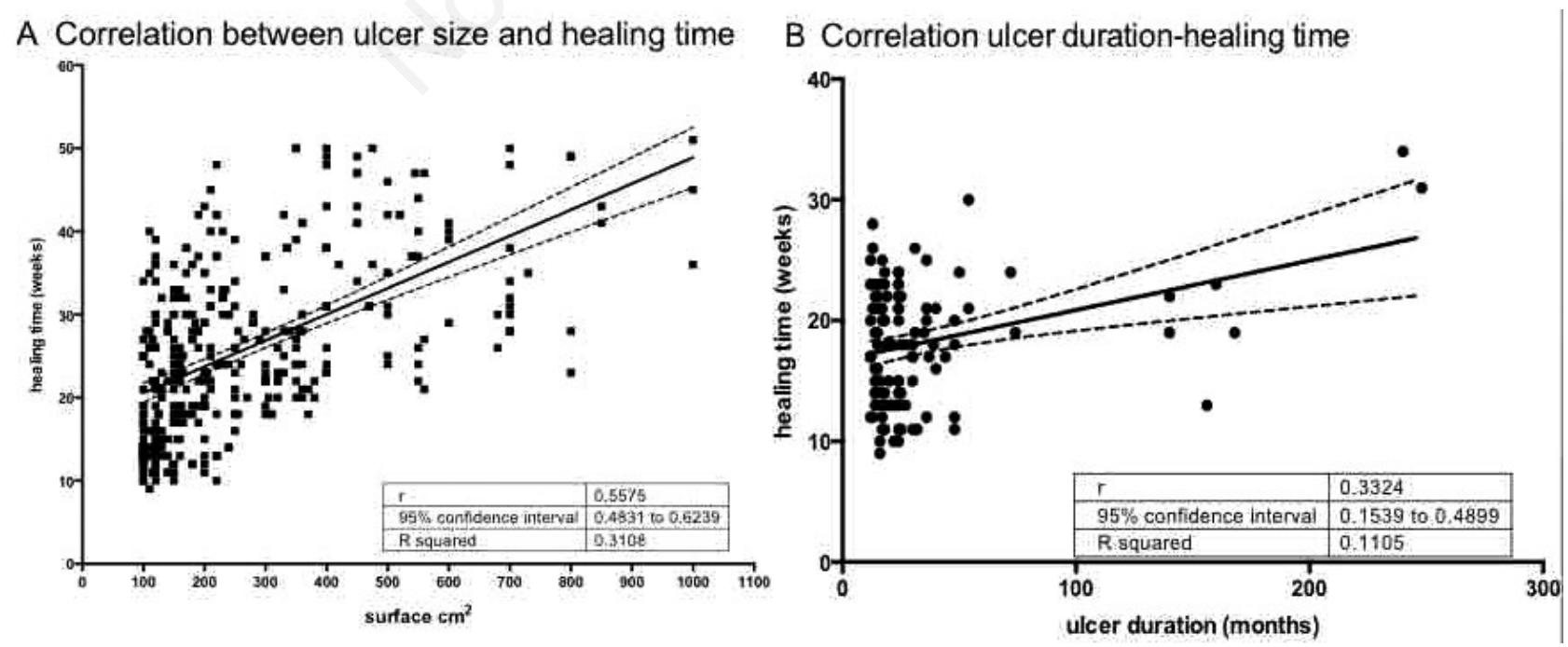

Figure 3. A) Healing time correlates with ulcer size and B) with ulcer duration: the larger the ulcer or the longer the duration, the longer the healing time. 
Exudate amount was effectively reduced by allografts from a pre-op value of 3 (IQR 2-3) to a post grafting value of 1 (IQR 1-1) $(\mathrm{P}<=.0001)$.

\section{DISCUSSION}

Autologous skin graft is considered the gold standard surgical therapy for skin repair but in full thickness skin ulcers the reconstruction dermal layer is necessary to rebuild structure and cell function of human skin. Skin substitutes are very effective achieving these targets. ${ }^{18,19}$ In particular DED, due to its delayed absorption (more than 4 weeks), ${ }^{20}$ after taking acts as a scaffold which is infiltrated by host cells, ${ }^{21}$ mainly fibroblasts and capillaries ${ }^{22}$ so promoting the reconstruction of a functional dermis..$^{23}$ The different steps of the allograft take and its replacement by granulation tissue at four weeks, which mediated the adhesion of the grafts to the underlying tissue, has been histologically shown. ${ }^{22}$ After granulation tissue formation allografts provide an appropriate matrix for the epithelial relining and for the growth of granulation tissue. ${ }^{22}$ In addition cryopreserved DED may release cytokines and growth factors due to their harvesting viable cells which may play an important role in restoring the impaired healing. ${ }^{24,25}$

Finally allograft does not leave any donor genetic material on the treated site. ${ }^{26}$

The effectiveness of donor skin grafting has been extensively proved since World War II in burn patients often affected by full thickness tissue loss and with poor chance for autologous skin harvesting. ${ }^{27-35}$

More recently donor skin has been used in different indications including non-healing leg ulcers, diabetic foot and ulcers with a dermatologic pathophysiology ${ }^{36-49}$ even with exposed muscle, tendon, and bone..$^{50}$ Also in these indications allografts proved to be effective in getting both the ulcer healing and a better scar quality and skin function. ${ }^{51-54}$

In our department we have been performing allografts for hard-to-heal leg ulcers with different pathophysiology for many years but this study reports only the most recent refractory ulcers as defined by extensive surface and long duration, two of the most important risk factors for delayed healing.., 10

109 out of 120 patients $(90.8 \%)$ healed proving that, even treating ulcers by sharp debridement and skin grafting, the healing time is still directly correlated with ulcer size, ulcer pathophysiology and ulcer duration. The majority of patients healed with one grafting procedure while forty-four patients received two grafts, which makes the treatment cost-effective specially considering the treated ulcers which were really refractory to heal.

Finally allografts are effective in reducing pain and exudate amount. Even if we didn't perform a specific Quality of Life analysis it is easy to understand that a significant reduction of pain and exudate (and, as a conse- quence, of smell), as reported in our case series, allowed an amazing improvement of quality of life of patients who could increase their daily activities and their participation in the social life.

Weak points of this report is the retrospective modality and the lack of control group. Nevertheless we wanted just to report our past experience with this treatment technique and offer a snapshot of what happens in the real life. In addition, when we started this treatment protocol, our intention was not to plan a prospective controlled trial because it is very difficult to identify a control group with a standard treatment in this kind of patients who were previously already submitted to many treatments for very long time without any success.

\section{CONCLUSIONS}

Allografts are extremely effective in favoring the ulcer healing also in case of extensive ulcers caused by different pathophysiology including arterial ulcer even in critical limb ischemia. They are effective in rebuilding deep layer loss, improving the ulcer bed even getting the ulcer healing or allowing new therapeutical procedures. The smallest the ulcer the higher the healing rate and the lowest the number of requested procedures. Skin ulcers in non-surgically treatable critical limb ischemia may heal but it is necessary take into account that the cumulative leg amputation and death rate is high $(62.5 \%)$. As soon as the deep layers have been reconstructed and only the epidermal layer is missing an autograft may speed up the healing process. Finally allografts are extremely effective in decreasing pain level and exudate amount so significantly improving patient's quality of live.

\section{REFERENCES}

1. Dale J, Callam M, Ruckley C. Chronic ulcers of the leg: A study of prevalence in a Scottish community. Health Bulletin 1983;41:310-4.

2. Graham ID, Harrison MB, Moffatt C, Franks P. Leg ulcer care: nursing attitudes and knowledge. Canadian Nurs 2001;97:19-24.

3. Nemeth KA, Harrison MB, Graham ID, Burke S. Understanding venous leg ulcer pain: results of a longitudinal study. Ostomy Wound Manage 2004;50:34-46.

4. Moffatt CJ, Franks PJ, Doherthy DC, Smithdale R, Martin R. Sociodemographic factors in chronic leg ulceration. Br J Dermatol 2006;155:307-12.

5. Agale SV. Chronic leg ulcers: epidemiology, aetiopathogenesis, and management. Ulcers 2013;2013. Available from: https://www.hindawi.com/journals/ulcers/2013/413604/

6. Khale B, Hermanns HJ, Gallenkemper G. Evidence-based treatment of chronic leg ulcers. Dtsch Arztebl Int 2011;108: 231-7.

7. Mosti G, De Maeseneer M, Cavezzi A, et al. Society for Vas- 
cular Surgery and American Venous Forum Guidelines on the management of venous leg ulcers: the point of view of the International Union of Phlebology. Int Angiol 2015;34:2012-218.

8. Sign Guideline. Management of chronic venous leg ulcers. A national clinical guideline, 2010.

9. Margolis DJ, Berlin JA, Strom BL. Risk factors associated with the failure of a venous leg ulcer to heal. Arch Dermatol 1999;135:920-6.

10. Milic DJ, Zivic SS, Bogdanovic DG, Karanovic ND, Golubovic ZV. Risk factors related to the failure of venous leg ulcers to heal with compression treatment. J Vasc Surg 2009;49:1242-7.

11. Mosti G, Mattaliano V. The debridement of chronic leg ulcers by means of a new, Fluidjet-based device. Wounds 2006;8:227-37.

12. Mosti G, Iabichella ML, Picerni P, Magliaro A, Mattaliano $\mathrm{V}$. The debridement of hard to heal leg ulcers by means of a new device based on Fluidjet technology. Int Wound J 2005;2:307-14.

13. Barwell JR, Davies CE, Deacon J, et al. Comparison of surgery and compression with compression alone in chronic venous ulceration (ESCHAR study): randomised controlled trial. Lancet 2004;363:1854-9.

14. Falanga V, Saap LJ, Ozonoff A. Wound bed score and its correlation with healing of chronic wounds. Dermatol Therapy 2006;19:383-90.

15. EU guidelines to good manufacturing practice medicinal products or human and veterinary use. Annex 1; 2008.

16. Linee guida per il prelievo, la processazione e la distribuzione dei tessuti a scopo di trapianto. Centro Nazionale per i Trapianti (CNT). 2016.

17. Commission Directive 2006/17/EC. Official J Eur Union 92-2006. L38/40-L38/52.

18. Decreto Legislativo 25 gennaio 2010, n. 16. Gazzetta Ufficiale n. 40. 18-2-2010.

19. Langdon RC, Cuono CB, Birchall N, et al. Reconstitution of structure and cell function in human skin grafts derived from cryopreserved allogeneic dermis and autologous cultured keratinocytes. J Invest Dermatol 1988;91:478-85.

20. Compton CC, Hickerson W, Nadire K, Press W. Acceleration of skin regeneration from cultured epithelial autografts by transplantation to homograft dermis. J Burn Care Rehabil 1993;14:653-62.

21. Pianigiani E, Taddeucci P, Mancini S, Miracco C. Wound healing in leg ulcers treated by combined skin allograft and autograft. J Invest Dermatol 2001;117:544.

22. Pianigiani E, Cherubini Di Simplicio F, Ierardi F, et al. Dermal allograft plus autologous epidermal graft: evaluation of two different techniques in chronic, nonhealing leg ulcers. Wounds 2004;16:91-6.

23. Omi T, Kawanami O, Matsuda K, Tsujii A, Kawai M, Henmi H, Ferrans VJ. Histological characteristics of the healing process of frozen skin allograft used in the treatment of burns. Burns 1996;22:206-11.

24. Fimiani M, Pianigiani E, Di Simplicio FC, et al. Other uses of homologous skin grafts and skin bank bioproducts. Clin Dermatol 2005;23:396-402.

25. Barrick B, Campbell EJ, Owen CA. Leukocyte proteinases in wound healing: roles in physiologic and pathological processes. Wound Repair Regen 1999;7:410-22.

26. Bucalo B, Eagelstein WH, Falanga V. Inhibition of cell proliferation by chronic wound fluid. Wound Repair Regen 1993;1:181-6.

27. Roseeuw DI, De Coninck A, Lissens W, et al. Allogic cultured epidermal grafts heal chronic ulcers although they do not remain as proved by DNA analisys. J Dermatol Sci 1990;1:245-52.

28. Brown JB, McDowell F. Massive repairs of burns with thick split-skin grafts; emergency 'dressings' with homografts. Ann Surg 1942;115:658-74.

29. Brown JB, McDowell F. Epithelial healing and the transplantation of skin. Ann Surg 1942;115:1166-77.

30. Brown JB, Minot PF, Randall P, Lu M. Postmortem homografts as 'biologicar dressings' for extensive burns and denuded areas. Ann Surg 1953;138:618-29.

31. Artz CP, Becker JM, Sako Y, Bronwell AW. Postmortem skin homografts in the treatment of extensive bums. AMA Arch Surg 1955;71:682-7.

32. Zaroff LI, Mills W Jr, Duckett JW Jr, et al. Multiple uses of viable cutaneous homografts in the burned patient. Surgery 1966;59:368-72.

33. Shuck JM. The use of homografts in burn therapy. Surg Clin North Am 1970;50:1325-35.

34. Pruitt BA Jr, Levine NS. Characteristics and uses of biologic dressings and skin substitutes. Arch Surg 1984;119:312-22.

35. Moerman E, Middelkoop E, Mackie D, et al. The temporary use of allograft for complicated wounds in plastic surgery. Burns 2002;28:S13-5.

36. Dhennin C, Desbois I, Yassine A, et al. Utilisation of glycerolised skin allografts in severe burns. Burns. 2002;28:S21-5.

37. Snyder RJ, Simonson DA. Cadaveric allograft as adjunct therapy for nonhealing ulcers. J Foot Ankle Surg 1999;38:93-101.

38. Snyder RJ. Treatment of nonhealing ulcers with allografts. Clin Dermatol 2005;23:388-95.

39. Spence RJ, Wong L. The enhancement of wound healing with human skin allograft. Surg Clin North Am 1997;77:731-45.

40. Teepe RG, Koebrugge EJ, Ponec M, et al. Fresh versus cryopreserved cultured allografts for the treatment of chronic skin ulcers. Br J Dermatol 1990;122:81-9.

41. Tzeng YS, Chen SG, Dai NT, et al. Clinical experience using cadaveric skin for wound closure in Taiwan. Wounds 2012:293-8.

42. Bakker K, Schaper NC. New developments in the treatment of diabetic foot ulcers. Ned Tijdschr Geneeskd 2000;144:409-12.

43. Brem H, Young J, Tomic-Canic M, et al. Clinical efficacy and mechanism of bilayered living human skin equivalent in treatment of diabetic foot ulcers. Surg Technol Int 2003;11:23-31.

44. Sanders L, Landsman AS, Landsman A, et al. A prospective, multicenter, randomized, controlled clinical trial comparing a bioengineered skin substitute to a human skin allograft. Ostomy Wound Manage 2014;60:26-38.

45. Landsman AS, Cook J, Cook E, et al. A retrospective clinical study of 188 consecutive patients to examine the effectiveness of a biologically active cryopreserved human skin allograft (TheraSkin $\left.{ }^{\circledR}\right)$ on the treatment of diabetic foot ulcers 
and venous leg ulcers. Foot Ankle Spec 2011;4:29-41.

46. Wollina U. Clinical management of pyoderma gangrenosum. Am J Clin Dermatol 2002;3:149-58.

47. De Imus G, Golomb C, Wilkel C, et al. Accelerated healing of pyoderma gangrenosum treated with bioengineered skin and concomitant immunosuppression. J Am Acad Dermatol 2001;44:61-6.

48. Chow RK, Ho VC. Treatment of pyoderma gangrenosum. J Am Acad Dermatol 1996;34:1047-60.

49. Rozen SM, Nahabedian MY, Manson PN. Management strategies for pyoderma gangrenosum: case study and review of literature. Ann Plast Surg 2001;47:310-5.

50. Kolenik SA 3rd, Leffell DJ. The use of cryopreserved human skin allografts in wound healing following Mohs surgery. Dermatol Surg 1995;21:615-20.

51. Wilson TC, Wilson JA, Crim B, Lowery NJ. The use of cry- opreserved human skin allograft for the treatment of wounds with exposed muscle, tendon, and bone. Wounds 2016; 28:119-25.

52. Li X, Meng X, Wang X, et al. Human acellular dermal matrix allograft: A randomized, controlled human trial for the long-term evaluation of patients with extensive burns. Burns. 2015;41:689-99.

53. Juhasz I, Kiss B, Lukacs L, et al. Long-term followup of dermal substitution with acellular dermal implant in burns and postburn scar corrections. Dermatol Res Pract 2010;2010:210150.

54. Norgren L, Hiatt WR, Dormandy JA, et al. on behalf of the TASC II Working Group. Inter-Society Consensus for the Management of Peripheral Arterial Disease (TASC II). J Vasc Surg 2007;45:S5-67. 